\title{
Relationship between hysterectomy and severity of female stress urinary incontinence
}

Fatemeh Heydari ${ }^{1}$, Zahra Motaghed ${ }^{2}$, Shahin Abbaszadeh ${ }^{1}$

${ }^{1}$ Assistant Professor, Department of Urology, Faculty of Medicine, Baqiyatallah University of Medical Sciences, Tehran, Iran

${ }^{2}$ M.D, Department of Urology, Faculty of Medicine, Baqiyatallah University of Medical Sciences, Tehran, Iran

\section{Type of article: Original}

\begin{abstract}
Background: Stress Urinary Incontinence (SUI) is one of the most reported health dilemmas of women suffering from lower urinary tract symptoms.

Aim: To determine the relation between hysterectomy and severity of female SUI using Valsalva Leak Point Pressure (VLPP).

Methods: This case-control study was conducted at a public urology clinic in Tehran in 2015. The study population was all female with SUI complaints who visited the clinic during 2015. We compared Valsalva leak point pressure in two groups of female SUI patients with and without hysterectomy history. The inclusion criteria were: not taking any alpha-blocker or anti-cholinergic medicines two weeks prior to the urodynamic test as well as no history of pelvic surgery or cesarean delivery in their lifetime. All qualified patients were invited to participate in the study randomly, and among them, 120 qualified patients agreed to participate by filling out the informed consent form. Data was gathered through direct interview, and double checked by patients' medical records. All the study variables including age, BMI, delivery number, hysterectomy and UTI history were entered and analyzed by estimating ordered logistic regression and by using Stata14.1 software.

Results: The mean of VLPP was $70.17 \mathrm{cmH}_{2} \mathrm{O}$ in the group with hysterectomy history, and $94.55 \mathrm{cmH}_{2} \mathrm{O}$ in those without hysterectomy history. The difference of VLPP pressure between the two studied groups were significant $(\mathrm{p}<0.05)$, even after control of confounding variables. Also, the odds of severe SUI among hysterectomy group patients was 6.3 times more than no hysterectomy $(\mathrm{OR}=6.32, \mathrm{p}<0.001)$.

Conclusions: Our study confirms significant relation between hysterectomy and SUI severity measured by Valsalva leak point pressure. Hysterectomy patients are more likely to suffer from more severe grades of SUI.

Keywords: Urinary Incontinence, Hysterectomy, Urodynamics, Valsalva Maneuver
\end{abstract}

\section{Introduction}

Stress urinary incontinence (SUI) is one of the most prevalent types of urinary incontinence (UI) in the world. It has been defined as any involuntary leakage of urine during sneezing, coughing or any physical exertion $(1,2)$. It's reported in most countries that 15 to $40 \%$ of women are faced with female SUI which are associated with severe disorders of women's daily functions, social interactions, sexuality, and psychological wellbeing. Therefore, SUI is increasingly being recognized as a global health concern $(2,3)$. SUI is one of the most reported health dilemmas of women suffering from Lower Urinary Tract Symptoms (LUTS)(4, 5). Although many modifiable and nonmodifiable risk factors for SUI are identified (such as age, delivery, BMI and pelvic surgery), still some of them, like hysterectomy, are less clear $(2,5)$. Identification of the possible risk factors of female SUI is important for the reduction of SUI prevalence, and can lead to females' health promotion as well as a decrease of direct and indirect health care costs to society (3). Nowadays, hysterectomy is the first choice or at least one of the most preferred choices in treatment of many diseases and disorders like menometrorrhagia, leiomyoma, uterine prolapse, adenomyosis and postmenopausal bleeding. It is preferred due to its low perioperative morbidity and its

\section{Corresponding author:}

Dr. Zahra Motaghed, Department of Urology, Faculty of Medicine, Baqiyatallah University of Medical Sciences, Tehran, Iran. Tel: +98.2182482476, Email: mailer.motaghed@gmail.com

Received: December 31, 2016, Accepted: March 08, 2017, Published: June 2017

iThenticate screening: February 09, 2017, English editing: March 19, 2017, Quality control: April 20, 2017

(C) 2017 The Authors. This is an open access article under the terms of the Creative Commons Attribution-NonCommercialNoDerivs License, which permits use and distribution in any medium, provided the original work is properly cited, the use is non-commercial and no modifications or adaptations are made. 
effectiveness as a definitive treatment and also its decisive role as a certain cure (3). The side effects of hysterectomy on function of lower-urinary-tract system have been a controversial issue for decades (3). There are many inconsistent opinions about the adverse effects of hysterectomy on SUI which have originated from previous studies (6). In this context, the study of Aoun and Roumeguère in 2015 has provided a comprehensive overview on postoperative lower urinary tract dysfunction. According to their study, lower urinary tract dysfunction is a common finding ( $70-85 \%$ prevalence) after hysterectomy, and its most frequent long term sequela is stress urinary incontinence ( $40 \%$ of cases) and its management is complex and challenging (4). Many studies similar to this have been done, but the question still remains whether there is any significant relation between hysterectomy and the severity of SUI. While it is generally known that the result of a urodynamic test can play a decisive role in understanding the presence and severity of SUI (7), in most of the previous studies, SUI has been determined through self-reported questionnaire based methods (8-10). The Valsalva leak point pressure (VLPP) obtained from urodynamic tests can easily help us in grading the severity of SUI $(7,11)$. VLPP indicates the pressure that is required to overcoming bladder resistance against increased pressure from the abdominal cavities during coughing or straining. Patients who are suffering from a severe grade of SUI are usually known by less than $60 \mathrm{cmH}_{2} \mathrm{O}$ VLPP while patients who are suffering from middle and weak grades of SUI are known by $60-90 \mathrm{cmH}_{2} \mathrm{O}$ and more than 90 $\mathrm{cmH}_{2} \mathrm{O}$ VLPP, respectively (12). Nevertheless, the relation between hysterectomy and level of stress urinary incontinence (SUI) measured by Valsalva leak point pressure (VLPP) had yet to be studied. Emphasizing the role of urodynamic test, the relation between hysterectomy and SUI severity has been determined in our study for the first time.

\section{Material and Methods}

This cross-sectional and case-control study was conducted at a public urology clinic in Tehran in 2015 . The study population was all female with SUI complaint who visited the clinic during 2015. We compared Valsalva leak point pressure (VLPP) in two groups of female SUI patients with and without hysterectomy history. The hysterectomy history was defined as any type of hysterectomy that has occurred at least one year ago, according to the report of patients' medical record. The emphasis on the passing of at least a year from hysterectomy surgery was due to considering the probability of spontaneous recovery of urinary symptoms 6-12 months' post operation. Also, based on the previous study (12), we categorized the severity of SUI into three grades including: 1 ) Mild SUI (VLPP $\geqslant 90$ $\mathrm{cmH}_{2} \mathrm{O}$ ), 2) Moderate SUI (VLPP $=60-89 \mathrm{cmH}_{2} \mathrm{O}$ ), 3) Severe SUI (VLPP $<60 \mathrm{cmH}_{2} \mathrm{O}$ ). The study inclusion criteria were: not taking any alpha-blocker or anti-cholinergic medicines two weeks prior to the urodynamic test as well as no history of pelvic surgery, cesarean delivery or abortion in their life time. According to our previous study, the average and standard deviation of VLPP was $78 \pm 16$ and $87 \pm 16$ respectively in each of the two groups of patients with and without hysterectomy history. Thus, the required sample size for the purpose of comparing the average of VLPP -as a quantitative dependent variable- among hysterectomies and non-hysterectomies was 100. Sample size has been calculated considering type I and type II errors as 0.05 and 0.20 respectively. All patients who met the inclusion criteria were invited to participate in the study randomly, and among them, 120 qualified patients showed their complete interest for participation voluntarily through filling out the informed consent form. Also, the study result reported respecting the confidentiality and anonymity of participants. All necessary data (including patients' age, weight, height, delivery numbers and UTI history) were gathered through direct interview, and double checked by patients' medical record. The history of UTI was defined as self-report of having UTI in a previous year. We used paired-samples t-test for comparing the mean of VLPP between two groups of patients, a group of patients who had hysterectomy history and another group who hadn't any hysterectomy history. We also utilized ordered-logistic regression and Analysis of Covariance (ANCOVA) for controlling the effects of confounding variables including age, BMI, UTI history and delivery numbers. All data were entered and analyzed using Stata14.1 software.

\section{Results}

Table 1 shows descriptive statistics of the studied variables among patients. About $50 \%, 39 \%$ and $11 \%$ of patients had mild, moderate and severe SUI, respectively according to their VLPP results. About $59 \%$ and $41 \%$ of patients had positive and negative history of UTI, respectively. About $59 \%$ of patients were in the 40 to 60 years-old range and $24 \%$ of them were over 60 years-old. According to BMI results $61 \%$ and $27 \%$ of patients had obesity and overweight respectively. Most of the patients (78\%) had history of at least one delivery. Table 2 shows the univariate analysis of the studied variables among patients. According to the findings, the mean of the Valsalva leak point pressure was $70.17 \mathrm{cmH}_{2} \mathrm{O}$ and $94.55 \mathrm{cmH}_{2} \mathrm{O}$ in two groups of patients respectively with hysterectomy history and without hysterectomy history. The difference in VLPP between the two groups was significant $(\mathrm{p}<0.001)$. The mean of Valsalva leak point pressure was significantly lower in the group of patients who had positive hysterectomy history $(\mathrm{p}<0.001)$. Also, the mean of the Valsalva leak point pressure was significant between different delivery 
number, age and BMI groups, except UTI (Table 2). Table 3 shows the Analysis of covariance (ANCOVA). According to ANCOVA results, after omitting the side effects of confounding variables (including UTI, delivery, age and BMI), the mean of VLLP in hysterectomy patients was significantly lower than non-hysterectomy patients $(\mathrm{p}<0.001)$. So there was a statistically significant difference between hysterectomy history and mean of the Valsalva leak point pressure even after controlling the effects of confounding variables $(\mathrm{p}<0.001)$. Finally, ordered-logisticregression was estimated for analyzing Odds Ratio (OR) for factors affecting SUI grade (Table 4). According to the results of ordered-logistic regression model (Table 4), hysterectomy group patients were significantly 6.3 times more at the risk of more severe SUI $(\mathrm{OR}=6.32, \mathrm{p}<0.001)$. Also, older patients were significantly more at the risk of more severe SUI $(\mathrm{OR}=1.053, \mathrm{p}=0.038)$. The effect of other variables including UTI history, BMI score and delivery number on SUI severity was not significant $(\mathrm{p}>0.05)$.

Table 1. Descriptive statistics of the studied variables among patients

\begin{tabular}{|c|c|c|c|c|c|}
\hline \multirow{2}{*}{\multicolumn{2}{|c|}{ Variables }} & \multicolumn{2}{|c|}{ Hysterectomy history } & \multirow{3}{*}{$\begin{array}{l}\mathrm{n} \\
60\end{array}$} & \multirow{3}{*}{$\begin{array}{l}\% \\
50 \\
\end{array}$} \\
\hline & & \multirow{2}{*}{$\begin{array}{l}\text { Yes } \\
13\end{array}$} & \multirow{2}{*}{$\begin{array}{l}\text { No } \\
47\end{array}$} & & \\
\hline VLPP $\left(\mathrm{cmH}_{2} \mathrm{O}\right)$ & $\geq 90$ & & & & \\
\hline & $60-89$ & 35 & 12 & 47 & 39.2 \\
\hline & $<60$ & 12 & 1 & 13 & 10.8 \\
\hline \multirow[t]{2}{*}{ UTI history } & Yes & 34 & 37 & 71 & 59.2 \\
\hline & No & 26 & 23 & 49 & 40.8 \\
\hline \multirow[t]{3}{*}{ Delivery Numbers } & 0 & 5 & 21 & 26 & 21.7 \\
\hline & $1-4$ & 42 & 35 & 77 & 64.2 \\
\hline & $\geq 5$ & 13 & 4 & 17 & 14.1 \\
\hline \multirow[t]{3}{*}{ Age (years old) } & $20-40$ & 0 & 20 & 20 & 16.7 \\
\hline & $40-60$ & 38 & 33 & 71 & 59.2 \\
\hline & $\geq 60$ & 22 & 7 & 29 & 24.1 \\
\hline \multirow[t]{3}{*}{ BMI $\left(\mathrm{kg} / \mathrm{m}^{2}\right)$} & $18.5-25$ & 14 & 0 & 14 & 11.7 \\
\hline & $25-30$ & 15 & 18 & 33 & 27.5 \\
\hline & $\geq 30$ & 45 & 28 & 73 & 60.8 \\
\hline
\end{tabular}

Table 2. Univariate analysis of the studied variables among patients

\begin{tabular}{|c|c|c|c|c|}
\hline \multirow{2}{*}{\multicolumn{2}{|c|}{ Variables }} & \multicolumn{2}{|l|}{ VLLP } & \multirow[t]{2}{*}{ p-value } \\
\hline & & Mean & SD & \\
\hline \multirow[t]{2}{*}{ Hysterectomy history } & Yes & 70.17 & 17.17 & \multirow[t]{2}{*}{$<0.001$} \\
\hline & No & 94.55 & 11.74 & \\
\hline \multirow[t]{2}{*}{ UTI history } & Yes & 83.3 & 18.6 & \multirow[t]{2}{*}{0.612} \\
\hline & No & 81.3 & 19.92 & \\
\hline \multirow[t]{3}{*}{ Delivery Numbers } & 0 & 96.9 & 10.87 & \multirow[t]{3}{*}{$<0.001$} \\
\hline & $1-4$ & 79.3 & 19.34 & \\
\hline & $\geq 5$ & 74.1 & 16.89 & \\
\hline \multirow[t]{3}{*}{ Age (years old) } & $20-40$ & 99.8 & 1.3 & \multirow[t]{3}{*}{$<0.001$} \\
\hline & $40-60$ & 82.2 & 19.28 & \\
\hline & $\geq 60$ & 70.6 & 15.89 & \\
\hline \multirow[t]{3}{*}{ BMI $\left(\mathrm{kg} / \mathrm{m}^{2}\right)$} & $18.5-25$ & 99.6 & 0.8 & \multirow[t]{3}{*}{$<0.001$} \\
\hline & $25-30$ & 84.6 & 19.98 & \\
\hline & $\geq 30$ & 78 & \pm 15.51 & \\
\hline
\end{tabular}

Table 3. Analysis of covariance (ANCOVA)

\begin{tabular}{|l|l|l|l|l|}
\hline Variables & Mean Square & F & Sig. \\
\hline Hysterectomy history & 8463.37 & 41.72 & $<0.001$ \\
\hline Controlled variables: & UTI history & 184.02 & 0.91 & 0.343 \\
\cline { 2 - 5 } & Delivery Numbers & 639.30 & 3.15 & 0.047 \\
\cline { 2 - 5 } & Age (years old) & 485.01 & 2.39 & 0.096 \\
\cline { 2 - 5 } & BMI $\left(\mathrm{kg} / \mathrm{m}^{2}\right)$ & 54.98 & 0.27 & 0.763 \\
\hline \multicolumn{4}{|l|}{} \\
\hline
\end{tabular}


Table 4. Results of ordered-logistic regression model for factors affecting SUI grade

\begin{tabular}{|l|l|l|l|l|l|l|}
\hline Variables & Coefficient & Odds Ratio & \multicolumn{2}{|l|}{$[95 \%$ Conf. Interval] for Odds } & $\mathrm{z}$ & $\mathrm{p}$-value \\
\hline Hysterectomy History $(+)$ & 1.843 & 6.321 & 2.53 & 15.76 & 3.95 & 0.000 \\
\hline UTI History $(+)$ & -0.401 & -0.669 & 0.28 & 1.55 & -0.93 & 0.351 \\
\hline Delivery Number & 0.146 & 1.157 & 0.85 & 1.55 & 0.97 & 0.334 \\
\hline Age (years) & 0.051 & 1.053 & 1.00 & 1.10 & 2.08 & 0.038 \\
\hline BMI Score $\left(\mathrm{kg} / \mathrm{m}^{2}\right)$ & 0.069 & 1.071 & 0.95 & 1.20 & 1.16 & 0.248 \\
\hline prob $>\mathrm{Chi}^{2}=0.0000$ & \multicolumn{7}{|l|}{} \\
\hline
\end{tabular}

\section{Discussion}

Our study confirms a significant relation between hysterectomy and SUI severity measured by Valsalva leak point pressure. The results showed that there is a significant relationship between hysterectomy history and VLPP of SUI patients. So the mean of Valsalva leak point pressure is significantly lower in hysterectomy patients and therefore, they are more likely to suffer from more severe grades of SUI. According to results of the ordered-logistic regression model, patients with positive hysterectomy history were significantly 6.32 times more at the risk of more severe SUI $(\mathrm{OR}=6.32, \mathrm{p}<0.001)$. However, decision-making about casual effects between hysterectomy and severity of SUI needs more studies using prospective methods. Future studies should be designed to evaluate casual effects of hysterectomy on SUI grade. Our findings suggest that hysterectomy history must be considered as an effective factor on severity of SUI, not only as a risk factor of SUI occurrence. However, our study confirms the results of Brown et al. (13), Altman et al. (3) and Allahdin et al. (14) studies. Brown, by using systematic review, concluded that the likelihood of incontinence is greater in women with hysterectomy history (13). Also, a 30-years cohort study by Altman et al. indicated that the rate of SUI surgery is significantly higher in the cohort exposed group (hysterectomy group) than the unexposed group (3). Allahdin et al.'s 10 years follow up study showed that total abdominal hysterectomy is associated with a significantly increased incidence of hospital referral for UI urological investigations and treatment (14). Moreover, there are some inconsistent studies. For example, a study by Tayrac et al. reveals no risk of SUI at long-term follow-up after vaginal hysterectomy (10). Similarly, Miller's study does not find any relationship between hysterectomy and the risk of SUI (15). The inconsistent results can be due to the type and design of studies. The type of hysterectomy and quality of hysterectomy surgery and its post-operation care can be different between studies that may clarify the differences in the results. The quality of surgery and its postoperation services were not completely equal between studies, but can have significant effect on the results. According to our study results, hysterectomy history must be considered as an effective factor on severity of SUI. So, we should suggest some points to clinicians and policy-makers. First and foremost, we should suggest the reduction of unnecessary hysterectomies. Clinicians should more think about the possibility of increasing severity of SUI post operation of hysterectomy, before any decision about optional hysterectomy. All other treatment options should be considered before hysterectomy as much as possible. Secondly, clinicians should explain about side effects of hysterectomy and also the possibility of raised odds of UI severity post hysterectomy operation. Thirdly, we suggest practitioners for prescribing biofeedback (pelvic floor exercises) after hysterectomy, in order to prevent possible severe SUI especially for patients who have other SUI risk factors. Finally, we should note some limitations of our study. First, our study considered all types of hysterectomy (Radical or non-radical) together. Second, our study didn't consider confounding variables related to life style including nutrition, smoking and also the confounding variables interactions. Therefore, considering the study limitations, any use of the study results should be regarded conservatively.

\section{Conclusions}

Using VLPP indicator, our study confirms significant relation between hysterectomy and SUI severity. The odds of severe SUI among hysterectomy group patients was significantly more than without hysterectomy patients. The findings suggest that hysterectomy history must be considered as an effective factor on severity of SUI, not only as a risk factor of SUI occurrence. Therefore, clinicians should more think about the possibility of increasing severity of SUI post hysterectomy. Prescribing pelvic floor exercises after hysterectomy is necessary in order to prevent possible severe SUI. However, future studies should compare adverse effects between different types of hysterectomy in order to determine which one is the safest method of hysterectomy.

\section{Acknowledgments:}

This manuscript is adapted from MD thesis of Baqiyatallah University of Medical Sciences. Here we thank Dr. Alireza Ghadian for comments that greatly improved the research quality. Also, we thank Dr. Zohre Naderi for her assistance and efforts in the research proposal approval process. 


\section{Conflict of Interest:}

There is no conflict of interest to be declared.

\section{Authors' contributions:}

All authors contributed to this project and article equally. All authors read and approved the final manuscript.

\section{References:}

1) Haylen BT, de Ridder D, Freeman RM, Swift SE, Berghmans B, Lee J, et al. An International Urogynecological Association (IUGA)/International Continence Society (ICS) joint report on the terminology for female pelvic floor dysfunction. Neurourol Urodyn. 2010; 29(1): 4-20. doi: 10.1002/nau.20798. PMID: 19941278.

2) Sangsawang B. Risk factors for the development of stress urinary incontinence during pregnancy in primigravidae: a review of the literature. Eur J Obstet Gynecol Reprod Biol. 2014; 178: 27-34. doi: 10.1016/j.ejogrb.2014.04.010. PMID: 24784708.

3) Altman D, Granath F, Cnattingius S, Falconer C. Hysterectomy and risk of stress-urinary-incontinence surgery: nationwide cohort study. Lancet. 2007; 370(9597): 1494-9. doi: 10.1016/S0140-6736(07)61635-3.

4) Aoun $F$, Roumeguère $T$. Lower urinary tract dysfunction following radical hysterectomy. Prog Urol. 2015; 25(17): 1184-90. doi: 10.1016/j.purol.2015.08.311. PMID: 26362076.

5) Zhang L, Zhu L, Xu T, Lang J, Li Z, Gong J, et al. A Population-based Survey of the Prevalence, Potential Risk Factors, and Symptom-specific Bother of Lower Urinary Tract Symptoms in Adult Chinese Women. Eur Urol. 2015; 68(1): 98-112. doi: 10.1016/j.eururo.2014.12.012. PMID: 25572826.

6) Stothers L, Friedman B. Risk factors for the development of stress urinary incontinence in women. Curr Urol Rep. 2011; 12(5): 363-9. doi: 10.1007/s11934-011-0215-z. PMID: 21938471.

7) Aoun F, Peltier A, Van Velthoven R. Lower urinary tract dysfunction in pelvic gynecologic cancer: The role of urodynamics. Adv Urol. 2014; 2014: 303958. doi: 10.1155/2014/303958. PMID: 25506360, PMCID: PMC4259142.

8) Plotti F, Angioli R, Zullo MA, Sansone M, Altavilla T, Antonelli E, et al. Update on urodynamic bladder dysfunctions after radical hysterectomy for cervical cancer. Crit Rev Oncol Hematol. 2011; 80(2): 323-9. doi: 10.1016/j.critrevonc.2010.12.004. PMID: 21277788.

9) Gustafsson C, Ekström $\AA$, Brismar S, Altman D. Urinary incontinence after hysterectomy-three-year observational study. Urology. 2006; 68(4): 769-74. doi: 10.1016/j.urology.2006.04.001. PMID: 17070350.

10) de Tayrac R, Chevalier N, Chauveaud-Lambling A, Gervaise A, Fernandez H. Is vaginal hysterectomy a risk factor for urinary incontinence at long-term follow-up? Eur J Obstet Gynecol Reprod Biol. 2007; 130(2): 258-61. doi: 10.1016/j.ejogrb.2006.01.032. PMID: 16876308.

11) EL-Hefnawy AS, Wadie BS. Severe stress urinary incontinence: Objective analysis of risk factors. Maturitas. 2011; 68(4): 374-7. doi: 10.1016/j.maturitas.2011.01.005. PMID: 21292413.

12) Kuo HC. Videourodynamic analysis of the relationship of Valsalva and cough leak point pressures in women with stress urinary incontinence. Urology. 2003; 61(3): 544-8. doi: 10.1016/S0090-4295(02)025001. PMID: 12639643.

13) Brown JS, Sawaya G, Thom DH, Grady D. Hysterectomy and urinary incontinence: a systematic review. Lancet. 2000; 356(9229): 535-9. doi: 10.1016/S0140-6736(00)02577-0. PMID: 10950229.

14) Allahdin S, Harrild K, Warraich QA, Bain C. Comparison of the long - term effects of simple total abdominal hysterectomy with transcervical endometrial resection on urinary incontinence. BJOG. 2008; 115(2): 199-204. doi: 10.1111/j.1471-0528.2007.01546.x. PMID: 17970792.

15) Miller JJ, Botros SM, Beaumont JL, Aschkenazi SO, Gamble T, Sand PK, et al. Impact of hysterectomy on stress urinary incontinence: an identical twin study. Am J Obstet Gynecol. 2008; 198(5): 565.e1-4. doi: 10.1016/j.ajog.2008.01.046. PMID: 18455535. 